${ }^{a}$ Authors contributed equally. $<$ Saskia.Spillekom-vanKoulil@ radboudumc.nl>
Maria TEUNISSEN ${ }^{1}$ Elke M.G.J. DE JONG ${ }^{1}$ Andrea W.M. EVERS ${ }^{2,3}$ Marieke M.B. SEYGER ${ }^{1}$

1. Oostveen $A M$, de Jager ME, van de Kerkhof PC, Donders $A R$, de Jong $E M$, Seyger MM. The influence of treatments in daily clinical practice on the Children's Dermatology Life Quality Index in juvenile psoriasis: a longitudinal study from the Child-CAPTURE patient registry. Br J Dermatol 2012; 167: 145-9.

2. Bostoen J, Bracke S, De Keyser S, Lambert J. An educational programme for patients with psoriasis and atopic dermatitis: a prospective randomized controlled trial. $\mathrm{Br} J$ Dermatol 2012; 167: 1025-31.

3. Fortune DG, Richards HL, Kirby B, Bowcock S, Main CJ, Griffiths $C E$. A cognitive-behavioural symptom management programme as an adjunct in psoriasis therapy. $\mathrm{Br} J$ Dermatol 2002; 146: 458-65.

4. Scheewe S, Schmidt S, Petermann F, Stachow R, Warschburger P. Long-term efficacy of an inpatient rehabilitation with integrated patient education program for children and adolescents with psoriasis. Dermatol Psychosom 2001; 2: 16-21.

5. Oostveen AM, Spillekom-van Koulil S, Otero ME, Klompmaker W, Evers AW, Seyger MM. Development and design of a multidisciplinary training program for outpatient children and adolescents with psoriasis and their parents. J Dermatolog Treat 2013;24:60-3.

6. Evers AW, Duller $P$, de Jong EM, et al. Effectiveness of a multidisciplinary itch-coping training programme in adults with atopic dermatitis. Acta Derm Venereol 2009; 89: 57-63.

7. Lewis-Jones MS, Finlay AY. The Children's Dermatology Life Quality Index (CDLQI): initial validation and practical use. Br J Dermatol 1995; 132: 942-9.

8. Evers AW, Duller $P$, van de Kerkhof $P C$, et al. The Impact of Chronic Skin Disease on Daily Life (ISDL): a generic and dermatology-specific health instrument. BrJ Dermatol 2008; 158: 101-8.

9. Stein RE, Jessop DJ. The impact on family scale revisited: further psychometric data. J Dev Behav Pediatr 2003; 24:9-16.

10. Lawson V, Lewis-Jones MS, Finlay AY, Reid P, Owens RG. The family impact of childhood atopic dermatitis: the Dermatitis Family Impact Questionnaire. Br J Dermatol 1998; 138: 107-13.

doi:10.1684/ejd.2016.2785

\title{
Squamous cell carcinoma on the lip arising from discoid lupus erythematosus: a case report and review of Japanese patients
}

Squamous cell carcinoma (SCC) is a rare but wellrecognized complication of longstanding discoid lupus erythematosus (DLE). Although few epidemiological studies concerning DLE-related SCCs in Japan exist, it has been estimated that the incidence of SCC arising in DLE lesions reaches $3.3 \%$, which is similar to that reported for Caucasians $(2.3 \%$ to $3.3 \%)$ [1,2]. SCC is relatively rare in Japan, and its incidence of 2.5/100,000 person-years [3] is much lower than that in Caucasians $(22.65 / 100,000$ personyears in England [4] and 7.2 to 153.4/100,000 person-years in the USA [5]). Although the exact epidemiology of DLE is not known, DLE is estimated to be linked to $0.8-4.6 \%$ of all precursor lesions of SCC in Japan.
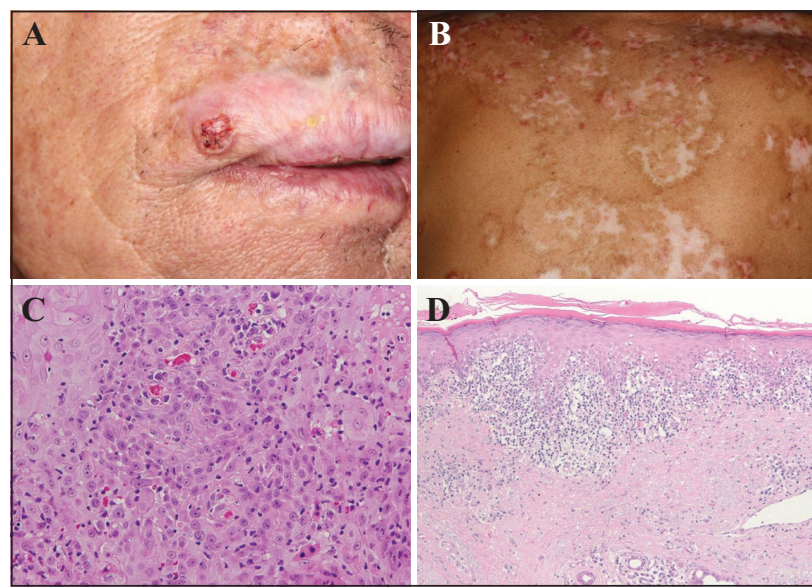

Figure 1. A) Clinical appearance of the squamous cell carcinoma (SCC) on the upper lip. B) Clinical appearance of discoid lupus erythematosus (DLE) lesions on the back. C) Histological aspect of the SCC (haematoxylin-eosin (HE) staining; original magnification: $\times 200)$. D) Histological findings of DLE lesion adjacent to the resected SCC (HE staining; original magnification: $\times 40)$.

We report a patient with SCC which developed on a DLE lesion of the upper and lower lip with cervical lymph node metastasis, and review 30 cases of DLE-related SCCs in the Japanese population.

A 68-year-old man with a 39-year history of DLE was referred to our department for a nodule on the upper lip which he had had for the last four months. Fourteen years before, he had developed SCC on the DLE lesion of the lower lip, accompanied by left cervical lymph-node metastasis. He subsequently underwent wide tumour resection and dissection of the left cervical lymph nodes. Physical examination revealed a reddish, dome-shaped, ulcerated nodule located on the atrophic DLE plaque of the upper lip, and multiple patches of DLE distributed on the face, hands, and back (figures $1 A, B$ ). Cervical lymph nodes were not swollen. Histological findings of a tumour biopsy were suggestive of moderately differentiated SCC (figure $1 C$ ). The SCC lesion was completely resected and the histological examination revealed the presence of vacuolar changes and intradermal lymphocyte infiltration adjacent to the resected tumour, corresponding to histological findings consistent with DLE (figure 1D). These findings provided further evidence that the SCC lesion was related to the pre-existing DLE lesion. There has been no evidence of local recurrence or distant metastasis to date.

Fifty-two SCCs in 30 cases of DLE-related SCC have been reported in the Japanese literature. These include 20 male and 10 female patients, with a male-to-female ratio of 2:1, despite the fact that DLE affects women approximately three times more often than men. A major factor that may contribute to this male predominance is considered to be ultraviolet (UV) radiation. Generally, in Japan, men work outdoors more frequently than women. Of all the reported DLE-related SCCs, 84.6\% (44/52) developed in sun-exposed areas of the body, particularly the lip (22/52; $44.3 \%$ ). These results also suggest that UV radiation is one of the most important factors involved in the development of SCCs on DLE lesions. The median latency period between onset of DLE and development of SCC on the lip (10 years; 
range: 2-32) is significantly shorter than that for SCCs arising at other sites (26 years; range: 5-47) (Mann-Whitney $U$ test; $p<0.05$ ). A shorter latency period for DLE-related SCCs developing on the lips has also been reported in Chinese and Indian patients [6,7]. Recurrence of multiple SCCs and lymph node metastases developed in eight $(27 \%)$ and three $(10 \%)$ of the 30 patients, respectively. In agreement with previous studies [8], these rates appear to be higher than those for non-DLE-related SCCs $(20 \%$ for recurrence and 0.5-6\% for metastasis) [9]. DLE-related SCCs are reportedly more aggressive than conventional SCCs on histological examination [6], which may provide a possible explanation for their more aggressive clinical behaviour. The present case is the first report of multiple DLE-related SCC associated with lymph node metastasis in Japan. The aggressive behaviour was attributed to the location on the lip and the moderate differentiation of the SCC on histological examination.

In conclusion, although SCC is relatively rare in Japan, DLE-related SCC is not uncommon. Sun protection, careful follow-up, and prompt skin biopsy is essential for patients with DLE, especially for SCCs developing on the lip. Once SCC has developed, sufficient attention should be paid to monitor possible recurrences and/or metastasis because of their more aggressive behaviour.

Disclosure. Financial support: none. Conflict of interest: none.

\author{
Department of Dermatology, \\ Hirosaki University Graduate \\ School of Medicine, \\ 5 Zaifu-cho, Hirosaki 036-8562, \\ Japan \\ <akasakae@hirosaki-u.ac.jp>
}

\section{Herpes zoster occurring on scars: two cases}

We report two patients who developed herpes zoster (HZ) on pre-existing scars, one of which developed at a site previously affected by $\mathrm{HZ}$.

Patient 1 was a 35-year-old woman who had undergone surgical removal of an osteoblastic osteosarcoma involving the left seventh rib. Thereafter, she received chemotherapy (methotrexate, cisplatin, and doxorubicin) every two months. She was referred to our department complaining of painful eruptions on the trunk that had appeared five months post-surgery. Physical examination showed small vesicles with surrounding erythema on and around the sutured scar (figure 1A). A Tzanck smear revealed multinucleated giant cells. In addition, a number of small freckles were observed on the lateral side of the abdomen. She was treated with valaciclovir (3,000 mg/day) for seven days.

Patient 2 was a 65-year-old woman suffering from IgA nephritis and hypogammaglobulinaemia, treated with oral prednisolone (2.5 $\mathrm{mg}$ every other day). She visited our department complaining of painful eruptions on the trunk that had appeared a few days before. Six months previously, she contracted HZ on the left T4-T5 dermatome, and was treated with oral antiviral drugs. Physical examination showed a number of erythematous seropapules and vesicles consistent with post-herpetic scars (figure 1B). A Tzanck smear revealed multinucleated giant cells. She was

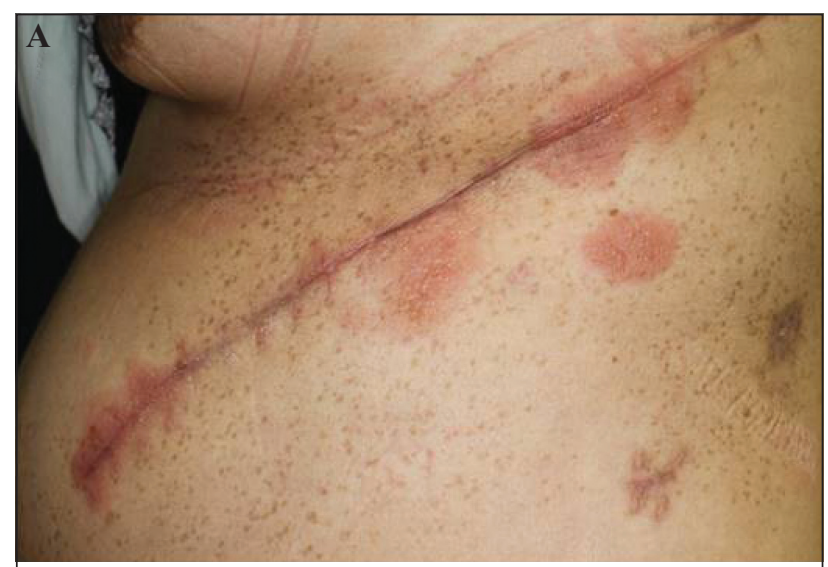

1. Millard LG, Barker DJ. Development of squamous cell carcinoma in chronic discoid lupus erythematosus. Clin Exp Dermatol 1978; 3: $161-6$.

2. de Berker $D$, Dissaneyeka $M$, Burge $S$. The sequelae of chronic cutaneous lupus erythematosus. Lupus 1992; 1: 181-6.

3. Kishikawa M, Koyama K, Iseki $M$, et al. Histologic characteristics of skin cancer in Hiroshima and Nagasaki: background incidence and radiation effects. Int J Cancer 2005; 1 17: 363-9.

4. Lomas A, Leonardi-Bee J, Bath-Hextall F. A systematic review of worldwide incidence of nonmelanoma skin cancer. $\mathrm{Br} J$ Dermatol 2012; 166: 1069-80

5. Karia PS, Han J, Schmults CD. Cutaneous squamous cell carcinoma: estimated incidence of disease, nodal metastasis, and deaths from disease in the United States, 2012. J Am Acad Dermatol 2013; 68: 957-66.

6. Tao J, Zhang X, Guo N, et al. Squamous cell carcinoma complicating discoid lupus erythematosus in Chinese patients: review of the literature, 1964-2010. J Am Acad Dermatol 2012;66: 695-6.

7. Fernandes MS, Girisha BS, Viswanathan N, et al. Discoid lupus erythematosus with squamous cell carcinoma: a case report and review of the literature in Indian patients. Lupus 2015;24: 1562-6.

8. Clayman GL, Lee JJ, Holsinger FC, et al. Mortality risk from squamous cell skin cancer. J Clin Oncol 2005; 23:759-65.

doi: $10.1684 /$ ejd.2016.2780

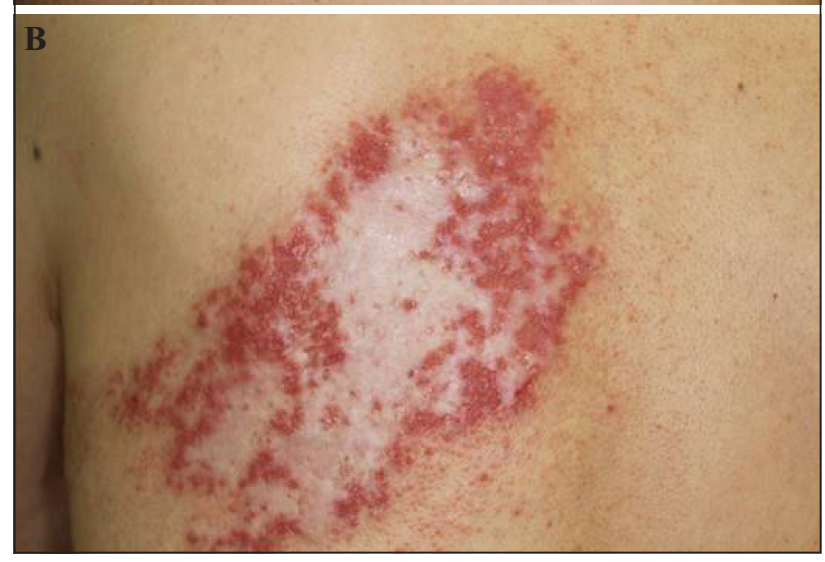

Figure 1. A) Small vesicles on and around the sutured scar. B) Herpes zoster on the herpes zoster scar on the back. 